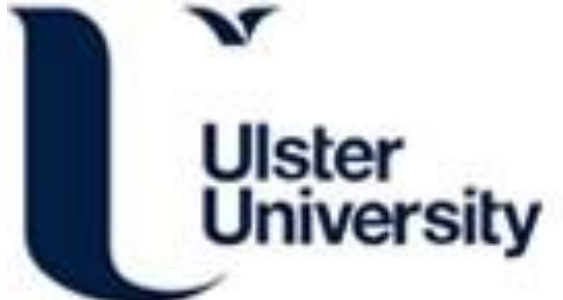

\section{Developing practice with health and social care professionals on smoking and pregnancy in Northern Ireland}

O'Doherty, E., Casson, K., Black, M., Hasson, F., \& Griffith, M. (2000). Developing practice with health and social care professionals on smoking and pregnancy in Northern Ireland. Health Education Journal, 59, $297-307$. https://doi.org/10.1177/001789690005900403

Link to publication record in Ulster University Research Portal

\section{Published in:}

Health Education Journal

Publication Status:

Published (in print/issue): 01/12/2000

DOI:

10.1177/001789690005900403

\section{Document Version}

Publisher's PDF, also known as Version of record

\section{General rights}

Copyright for the publications made accessible via Ulster University's Research Portal is retained by the author(s) and / or other copyright owners and it is a condition of accessing these publications that users recognise and abide by the legal requirements associated with these rights.

\section{Take down policy}

The Research Portal is Ulster University's institutional repository that provides access to Ulster's research outputs. Every effort has been made to ensure that content in the Research Portal does not infringe any person's rights, or applicable UK laws. If you discover content in the Research Portal that you believe breaches copyright or violates any law, please contact pure-support@ulster.ac.uk. 


\title{
Developing practice with health and social care professionals on smoking and pregnancy in Northern Ireland
}

\author{
Elaine O'Doherty, Karen Casson, Mary Black, Felicity Hasson, \\ Maureen Griffith
}

\begin{abstract}
This paper describes Phases One and Two of a project on smoking cessation in pregnancy: the process of reaching consensus and developing feasible, evidence-based guidelines. Phase Three of the project is piloting the guidelines, and Phase Four is ascertaining how women feel about use of the guidelines. The framework of nine key points is for use by any health and social care professional, and is being piloted in one health and social services board area in Northern Ireland. It is envisaged that the impact of the framework will be complemented by local policy, and education and training on holistic approaches for professionals.
\end{abstract}

Keywords: smoking cessation, pregnancy, Northern Ireland

\section{INTRODUCTION}

Smoking in pregnancy remains one of the few potentially preventable factors associated with low birthweight babies ${ }^{1-3}$, and is thought to account for one third of the incidence of perinatal and neonatal mortality ${ }^{4-5}$. Recent research has shown that one of the strongest carcinogens in tobacco smoke is transmitted to the developing foetus when a pregnant woman smokes ${ }^{6}$. Smoking can cause complications of pregnancy and labour ${ }^{7,8}$, as well as leading to premature delivery ${ }^{7,9,10}$. A number of authors $\mathrm{s}^{4,71,1,12}$ have found that the rate of spontaneous abortion is substantially higher among smokers. A combination of smoking during pregnancy

\footnotetext{
Elaine O'Doherty, Commissioning Officer for Health Promotion, NHSSB (at time of research: Senior Health Promotion Officer, Homefirst Community Trust). Karen Casson, Lecturer, University of Ulster, Newtownabbey, County Antrim, BT37 0OB, Northern Ireland (at time of research: Senior Research Officer, Department of Public Health Medicine, NHSSB). Mary Black, Health Action Zone Leader, North and West Belfast (at time of research: Commissioning Officer for Health Promotion, NHSSB). Felicity Hasson, Research Manager, Simon Community, Belfast (at time of research: Research Assistant, Centre for Nursing Research, University of Ulster). Maureen Griffith, Assistant Director of Nursing and Consumer Services, NHSSB. Correspondence to Karen Casson.
} 
and continued exposure to tobacco smoke increases the incidence of Sudden Infant Death Syndrome (SIDS), ${ }^{7,}$, with more than one quarter of the risk estimated as being attributable to maternal smoking ${ }^{5}$. Ill effects on the baby can include wheezy respiratory illness ${ }^{14}$, congenital defects ${ }^{15}$ and implications for long-term physical growth and development of the child ${ }^{16}$.

As in other parts of the United Kingdom (UK), smoking patterns in Northern Ireland reflect a strong social-class gradient. This pattern of women smoking is associated with a number of measures of social disadvantage ${ }^{17}$ which indicate that a cumulative exposure to disadvantage increases the risk of smoking among women. Evidence suggests that while women know that tobacco use is damaging their health, smoking paradoxically remains, for many women, an important means of coping with poverty, disadvantage and lack of control over other aspects of life ${ }^{18}$.

National targets have been set to reduce smoking rates in the general population. Government strategies ${ }^{19-21}$ all highlight the public health consequences of smoking. The White Paper on tobacco, Smoking Kills ${ }^{22}$ has set a national target to reduce the percentage of women who smoke during pregnancy from 23 to 15 per cent by the year 2010 , with a fall to 18 per cent by the year 2005 . It is true that many pregnant women (approximately $27-33$ per cent) give up smoking during pregnancy ${ }^{23}$. This fact, coupled with the knowledge that the majority of smokers (70 per cent of adult smokers) ${ }^{24}$ say that they want to stop smoking, presents an important opportunity which the current project seeks to exploit. At the same time the project recognises the limitations of adopting measures known to be effective, in isolation from other factors influencing women's lives. This meant the project had to go beyond the medical model of health ${ }^{25}$ which tends to be expert-led and can disempower people. Therefore, the project was based on the Beattie Model of health education ${ }^{26}$ which advocates that interventions are led by professionals, but are negotiated with individuals. It was premised on the need to support a range of approaches which seek to address pressures on women living in disadvantaged circumstances.

An important step for the project was to establish the current position of smoking among pregnant women in the Northern Health and Social Services Board (NHSSB) area of Northern Ireland. Although no routine local data were available, baseline data against which to set and monitor the progress of local targets were obtained from the Child Health System (a computerised system used by the four Health and Social Services Boards in Northern Ireland). However, there are acknowledged limitations with the scope of this information. Figure 1 shows that while the rate for smoking in pregnancy in the Northern Board area falls at the lower end of the rates estimated in national surveys ${ }^{7,23,27,28}$ ( 23 to 32 per cent), rates remain high and there has been no marked downward trend for the period 1995-1998.

To achieve a reduction in these rates the Northern Board has agreed annual targets of a 1 per cent reduction with its three main providers of maternity services (United Hospitals, Homefirst Community, and Causeway Health and Social Services Trusts) since 1997. The targets gave impetus to the project and were agreed by senior management, ensuring high levels of commitment across the relevant organisations. Further consultation with professional and line managers brought increased support and raised awareness of the need for co-operative working in this area.

The project group was aware, from a range of professional opinion and local 
FIGURE 1 Smoking in pregnancy rates, NHSSB hospitals 1995-1998

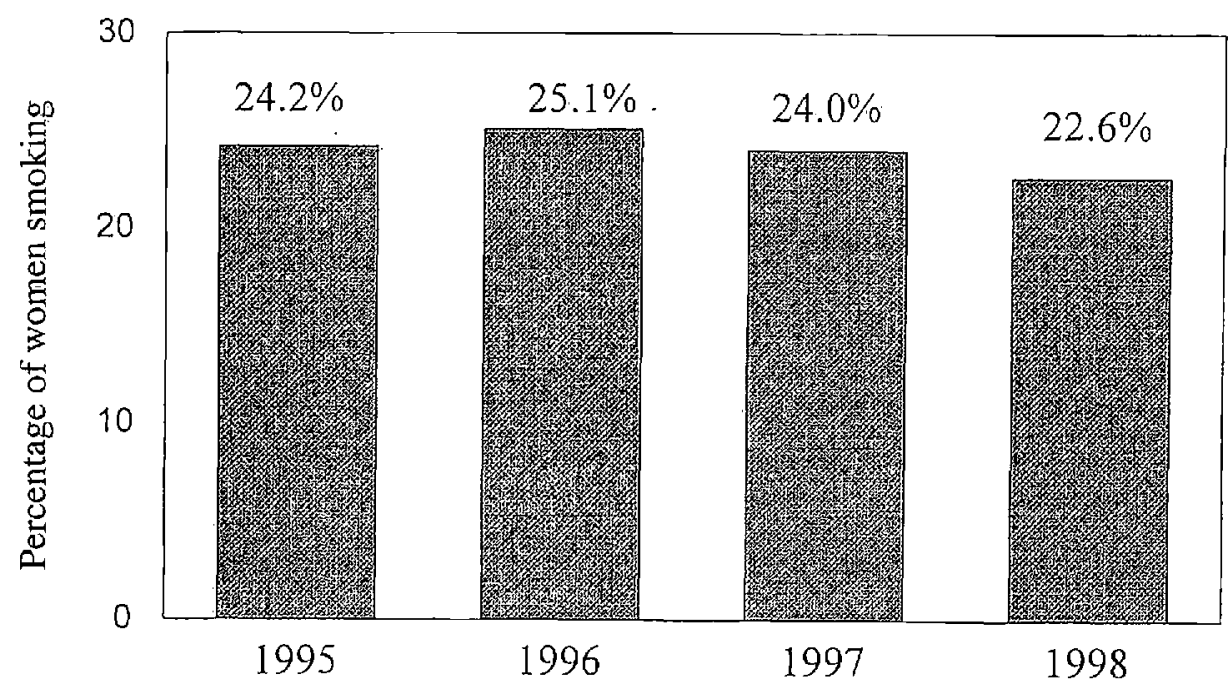

training seminars, of varied practice, and recognised the need to develop a consistent approach among local health and social care professionals to smoking cessation interventions of proven effectiveness. It was in recognition of the need to develop a co-ordinated approach to smoking cessation in pregnancy that a multiprofessional Smoking and Pregnancy Group was established in October 1997 by the main commissioner (NHSSB) and the three local Trusts which provide health and social care services. The work sought to strengthen the link between academic study and professional practice in the field.

The main outcome of this project will be the development of consistent guidelines for staff, to enable them to be well placed to give the best and most sensitive advice to women at this time in their lives. This is one step among a range of other measures that are required to tackle the issues of women and smoking in a holistic fashion. The need to take women's views into account as part of the development of the guidelines is addressed in Phase Four. This first stage of the process focused on gathering professional views and assessing the evidence of effectiveness.

The objectives of the first part of the study, which is reported below, were to:

- identify local health and social care staff with expertise in smoking cessation in pregnancy interventions, to represent their various professions;

- explore, by means of the Delphi Technique, which smoking cessation in pregnancy interventions were considered by the respondents to be best practice and to be feasible;

- consult, employing data triangulation, acknowledged sources of expertise in the field of smoking cessation in pregnancy interventions;

- extract from the data, using content-analysis methodology, the main areas of consensus among respondents on smoking cessation in pregnancy interventions;

- develop guidelines, based on consensus among local health and social care professionals, on smoking cessation in pregnancy interventions that are both feasible and of proven effectiveness. 


\section{METHODS}

There were two strands to the research methodology; systematic reviews were used to inform the effectiveness of interventions and guidelines, with the Delphi Technique being the research tool used to address the issue of the feasible implementation of national guidelines at a local level. A modified version of the Delphi Technique was used to achieve consensus among professionals on: firstly, essential and best practice; and, secondly, the most effective and feasible approaches to smoking cessation for pregnant women. Using purposive sampling, a total of 74 professionals were invited to participate on the basis of their professional experience and their commitment to smoking cessation. Table 1 shows the breakdown of professional groups and their response rates to each round.

In Phase One, participants were asked, using a postal survey, to state what they thought were the top five issues they would consider to be essential and best practice for helping women to stop smoking during pregnancy. From these responses, a composite list was devised and put alongside good practice identified from the literature, for use in Phase Two. In keeping with acknowledged good practice in guideline development ${ }^{29-31}$, the literature review focused mainly on validated national guidelines ${ }^{32,33}$. The list in Table 2 includes individual-focused interventions, but also takes account of the need to create support in the wider environment. The wording used by participants, with minor editing, is shown in this list. The Phase Two listing was posted to respondents, who were asked to identify those interventions they thought were best practice, and those they thought were feasible. They were also asked to rank in order of priority the eight interventions that they considered to be both best practice and feasible.

\section{RESULTS}

Of the 74 professionals who were invited to participate in the Delphi Technique, 47 took part in Phase One; a response rate of 64 per cent. Of these, 83 per cent

TABLE 1 Professional groups participating in Phases One and Two of the project

\begin{tabular}{lccc}
\hline $\begin{array}{l}\text { Health and social care } \\
\text { professionals }\end{array}$ & $\begin{array}{c}\text { Initial } \\
\text { sample }\end{array}$ & Phase One & Phase Two \\
\hline Consultants & 3 & 2 & 1 \\
General practitioners & 9 & 6 & 5 \\
Pharmacists & 5 & 3 & 2 \\
Social workers & 5 & 3 & 2 \\
Radiographers & 5 & 3 & 2 \\
Health visitors & 14 & 9 & 9 \\
Midwives & 21 & 13 & 12 \\
Community midwives & 12 & 8 & $39(83 \%)$ \\
Total & 74 & $47(64 \%)$ & \\
\hline
\end{tabular}

Figures in brackets are response rates to each phase. 


\section{BOX 1 Framework of nine key points on smoking and pregnancy}

1 Ask about smoking status at each contact

2 Assess intention to quit

3 Strongly urge quitting

4 Offer your support with quitting

5 Establish knowledge of dangers of smoking in pregnancy

6 Offer information about dangers of smoking and stress the benefits of quitting

7 Help to develop a quit plan

8 Identify support services available

9 Educate partner/family about the risks of active and passive smoking

(39/47) remained committed at Phase Two. The data from the ratings of Phase Two were analysed, and statistical summaries for each item computed to derive the top eight interventions identified under these categories as shown in Table 2. A number of points tied with equally high scores which would have given ten interventions, as opposed to the eight requested. Two of these were combined as one key point in order to streamline the guidelines and to ensure that the positive aspects of quitting were given equal emphasis ${ }^{34}$.

Having regard for the intended major use of the guidelines (ie as standards for ongoing development at organisational and specialist levels) it was agreed that the decision about exclusion or inclusion of items would be based solely on the final group vote for each item. Due to tied rankings, nine top choices emerged. The resulting guidelines, shown in Box 1 , reflect the consensus of local professionals. Before being produced for piloting in Phase Three, experts from the University of Ulster and the University of Southampton, with a proven track record in the field of smoking cessation, were consulted to ensure quality and appropriateness.

\section{DISCUSSION}

This project was designed to improve practice, not simply to develop and disseminate guidelines. A prerequisite for changing practice is the participation of key stakeholders in the process, in order to ensure ownership at a local level. The Delphi Technique has the advantages of: achieving concurrence in an area where none previously existed; reaching a research population which has diverse backgrounds with respect to experience or expertise; accommodating the involvement of more subjects than can effectively interact in a face-to-face-exchange; overcoming the obstacles of time, cost and logistics of frequent meetings; and reaching consensus using subjective judgements about how best to address the issue at a local level ${ }^{35}$. The fact that a wide range of professional groupings work with pregnant women provided a sound rationale for using this technique in the project. The Delphi Technique also has a number of limitations, including the use of 'experts' and poor response rates. In this project the first of these limitations was. mitigated by using those professionals who were committed to smoking cessation. There was a response rate of 64 per cent in Phase One, with 83 per cent of these remaining committed at Phase Two.

It is noteworthy that there is a variance between the issues professionals perceive 


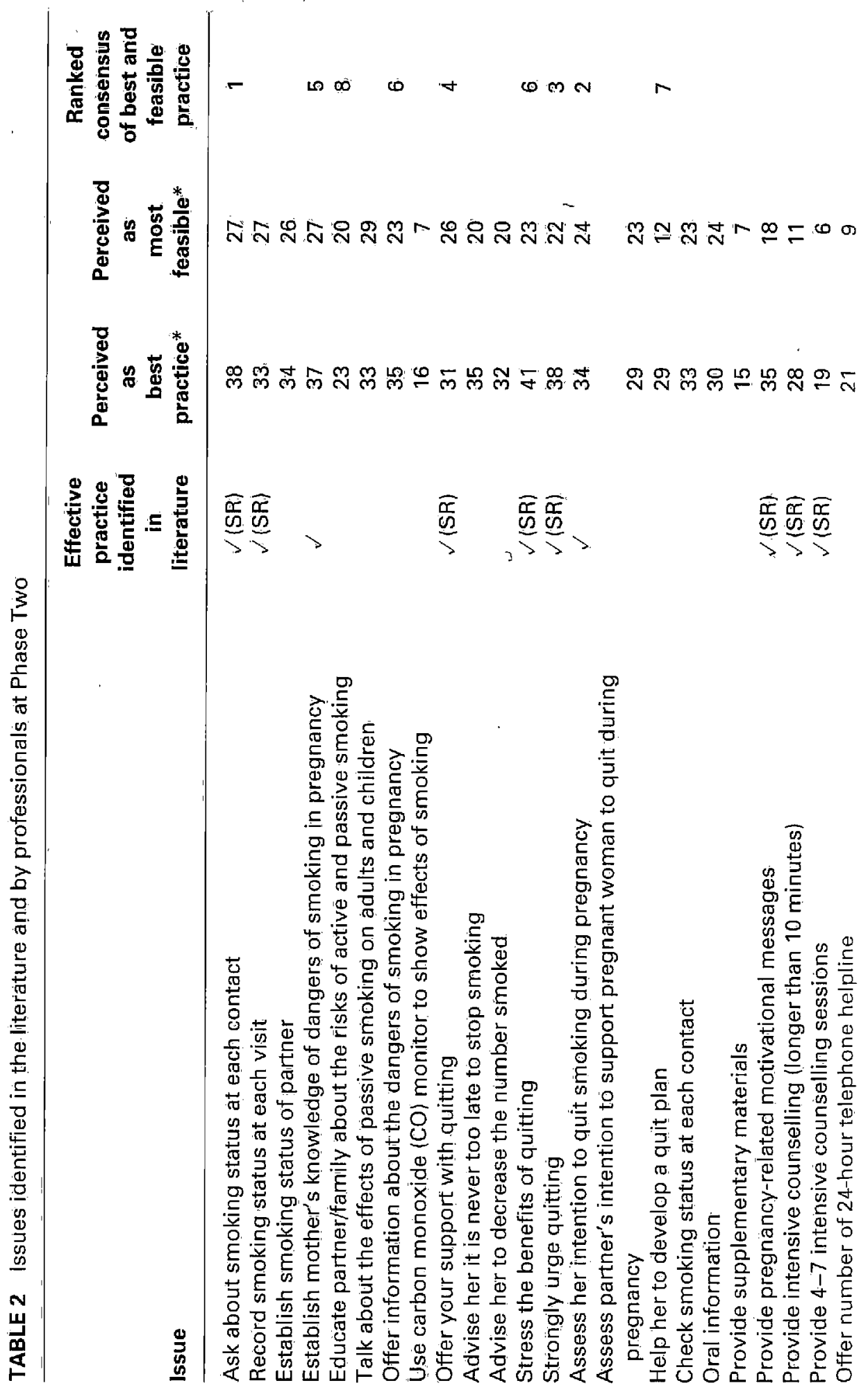




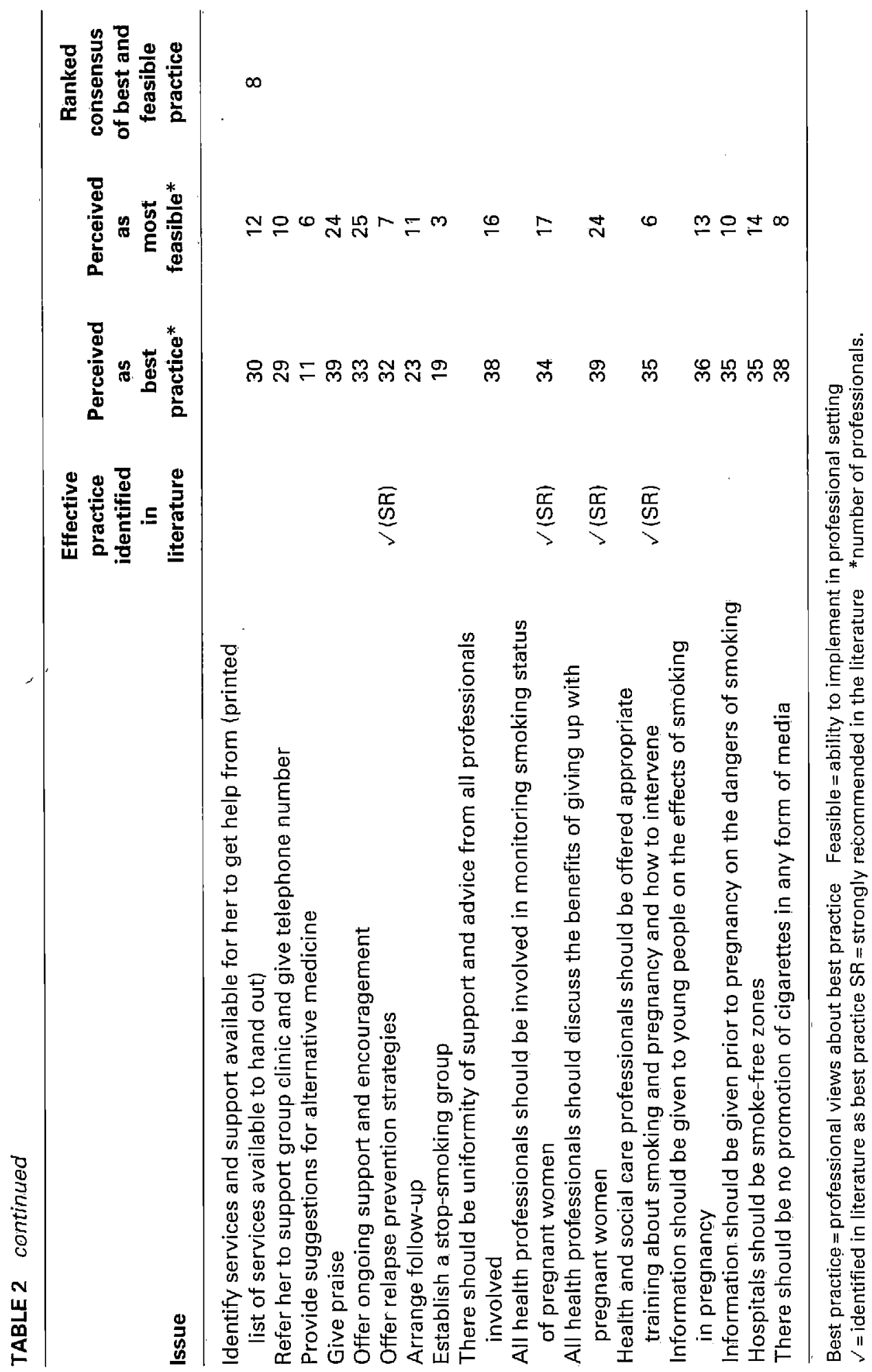


independently as being best practice or feasible practice, and those which they rank as best practice plus being feasible. It is equally significant that there is substantial consistency in the issues ranked by the professionals at Phase Two. For example, while respondents identified the recording of smoking status (Table 2, item 2) as good practice and as being feasible, it was not included in the overall ranking. It is acknowledged that within this project the experts' responses may not have been strictly independent, as discussion may have taken place within professional groups. However, the research does provide significant insight into feasible approaches to smoking cessation and pregnancy on which further research programmes may be based. Encouragingly, with regard to the Delphi Technique, many participants stated that responding to the questionnaire had in itself made them review their work role and that of their organisation. They had found this to be beneficial.

At the outset the Smoking and Pregnancy Group took a holistic view of smoking in pregnancy, recognising the constraints experienced by many pregnant women trying to quit smoking ${ }^{17,18,36}$. It was felt that health and social care professionals needed to be able to modify their approach to suit a range of circumstances. The advantages of adhering to the Beattie Model of health education are that: it acknowledges the local context; it allows professionals to take account of the health-professional/pregnant-smoker relationship, the setting in which the intervention takes place and the wider social enviromment of women; and it enables the individual to participate in the process. Underpinning the guidelines with the Beattie typology permits the professional to tailor the intervention to the circumstances and needs of individuals, ensuring that realistic goals are established which are meaningful to the women themselves. The project seeks to avoid 'victimblaming', while at the same time ensuring that professionals provide consistent advice, information and support to women. The guidelines are a framework only, from which to select a brief or intensive intervention, and need to be supported by policy development, educational materials and professional, education and training updates.

The dearth of good data on smoking in pregnancy has caused difficulties elsewhere in the $\mathrm{UK}^{37,38}$. The need for better quantitative information has been recognised by the Smoking and Pregnancy Group, and proposals have been made for the future collection and retrieval of information through a separate route that will link into a regional strategy on data collection. The proposed new dataset will provide a more robust baseline for prevalence rates, allow feedback to professionals, and aid the accurate monitoring of progress towards targets.

Intrinsic to the work of the Smoking and Pregnancy Group has been the cooperative style of working between commissioners, providers and academia. This mode of working is acknowledged as current best practice in health promotion ${ }^{39}$. It is singularly important in a world of competing priorities and agencies' own agendas that those in senior management positions recognise the importance of the work. A number of steps were taken to secure this commitment. Initially targets were agreed between the commissioner and providers. All relevant organisations were invited to participate in the Smoking and Pregnancy Group, initially as a support mechanism to achieve the targets. However, the Group quickly acknowledged that real progress would demand real change, in terms of policy, advice, information recording and, most significantly, staff time. Inviting senior managers to a seminar to discuss the best way forward in both developing and implementing 
the guidelines reinforced ownership and commitment. Senior staff in the Northern Health and Social Services Board endorsed the project and consistently highlighted the issue in commissioning plans. These steps were important, not only to achieve a flow of information, but also to ensure that this issue received sufficient attention among other pressing demands such as hospital waiting lists and development of acute services. It has also been important to set the initiative in the context of general policy, which advocates the need to address inequalities in health, a central theme in the Regional Strategy for Health and Social Wellbeing ${ }^{20}$.

The process of collaboration has yielded particular benefits and has led to resources being secured. In particular, imaginative use has been made of funds provided for supporting the findings of the Confidential Enquiry into Stillbirths and Deaths in Infants (CESDI) by employing dedicated research expertise. Significant human resources have been devoted to the development of the guidelines through the commitment of senior management. This has produced a sense of ownership of the project which has continued throughout the remaining two stages of the project.

Good practice demands effective dissemination and piloting of the guidelines. Key to effective dissemination ${ }^{40}$, is the development of a two-way exchange based on a foundation of trust and mutual benefit between researchers and implementer groups. These principles have underpinned the development of the project to date and are reflected in the wide consultation undertaken at all levels with key representatives of the participating disciplines. The final stages are nearing completion; piloting of the guidelines at a range of sites - hospital, community, GP practice, dental practice and pharmacy - and the assessment of the views of pregnant women who smoke are currently underway. Following evaluation it is the intention to implement the guidelines throughout the Northern Board area.

\section{Acknowledgements}

The authors gratefully acknowledge the support and assistance given to this project by many colleagues, in particular: the Board and Senior Managers of the Northern Health and Social Services Board; the provider Trusts; the members of the Smoking and Pregnancy Group; the health and social care staff who participated in the Delphi Technique; and for helping in the design and analysis of the project, Ms Liz Batton, Consultant in Behaviour and Health, University of Southampton, Ms Deirdre Fullerton, Lecturer, University of Ulster, and Professor Hugh McKenna and staff in The Centre for Nursing Research, University of Ulster.

\section{References}

1 Sexton M, Hebel JR. A clinical trial of change in maternal smoking and its effects on birthweight. Joumal of the American Medical Association 1984: 251: 911-15.

2 Li CQ, Windsor RA, Perkins L, Goldenberg RL, Lowe RB. The impact on infant birthweight and gestational age of cotinine validated smoking reduction during pregnancy. Jounal of the American Medical Association 1993: 269: 1519-24.

3 MacArthur C, Newton JR, Knox EG. Effect of anti-smoking health education on infant size at birth: a randomised controlled trial. British Joumal of Obstetrics and Gynaecology 1987: 94: 295-300. 
4 Walsh RA. Effects of maternal smoking on adverse pregnancy outcomes: examination of the criteria of causation. Human Biology 1994: 66: 1059-92.

5 Royal College of Physicians. Smoking and the Young. A Report of a Working Party of the Royal College of Physicians. London: RCOG, 1992.

6 Wișe J. Carcinogen in tobacco smoke can be passed to fetus. British Medical Journal 1998: 317: 555 .

7 Bolling K, Owen L. Smoking and Pregnancy. A Survey of Knowledge, Attitudes and Behaviour. London: HEA, 1997.

8 Poswilla D, Alberman E. Effects of Snoking on the Fetus, Neonate and Child. Oxford: Oxford University Press, 1992.

9 McDonald AD, Armstrong BG, Sloan M. Cigarette, alcohol and coffee consumption and prematurity. Americain Joumal of Public Health 1992: 82: 87-90.

10 Meyer MB, Jonas BS, Tonascia JA. Perinatal events associated with maternal smoking during pregnancy. American Joumal of Epidemiology 1976: 103: 464-76.

11 Armstrong BG, McDonald AF, Sloan M. Cigarette, alcohol and coffee consumption and spontaneous abortion. American Journal of Epideniology 1992: 108: 470-79.

12 Himmelberger DU, Brown BW, Cohen EW. Cigarette smoking during pregnancy and the occurrence of spontaneous abortions and congenital abnormality. American Jounal of Epidemiology 1997: 108: 1519-24.

13 Klonoff-Cohen HS, Edelstein SL, Lefkowitz ES et al. The effect of passive smoking and tobacco exposure through breast milk on sudden infant death syndrome. Joumal of the American Medical Association 1995: 273: 795-8.

14 Stoddard J, Miller T. Impact of paternal smoking on the prevalence of wheezing respiratory illness in children. American Journal of Epidemiology 1995: 141: 96-102.

15 Haddow JE, Palomaki GE, Holman MS. Young maternal age and smoking during pregnancy as risk factors for gastroschisis. Teralology 1993: 47: 225-8.

16 Fogelman KR, Manor O. Smoking in pregnancy and development into early adulthood. British Medical Joumal 1988: 297: 1233-6.

17 Graham $\mathrm{H}$. Promoting health against inequality: using research to identify targets for intervention - a case study of women and smoking. Health Education Jounal 1998: 57: 292-302.

18 Graham H. When life's a Drag: Women, Smoking and Disadvantage. London: HMSO, 1993.

19 Department of Health. The Health of the Nation. A Strategy for Health in England. London: HMSO, 1992.

20 Department of Health and Social Services. Health \& Wellbeing: into the Next Millennium. Regional Strategy for Health and Social Wellbeing 1997-2002. Belfast: DHSS, 1997.

21 Department of Health and Social Services. Well into 2000. A Positive Agenda for Health and Well-being. Belfast: DHSS, 1997.

22 Department of Health. Simoking Kills. A White Paper on Tobacco. London: The Stationery Office, 1998.

23 Foster K, Lader D, Cheeseborough S. Infant Feeding 1995. Office of Population Censuses and Surveys. London: HMSO, 1997.

24 Callum C. The UK Smoking Epidemic: Deaths in 1995. London: HEA, 1998.

25 French J. Boundaries and horizons, the role of health education within health promotion. Health Education Joumal 1990: 49(1): 7-10.

26 Beattie A. Knowledge and control in health promotion: a test case for social policy and social theory. In: Gabe J, Calnan M, Bury M (eds), The Sociology of the Health Service. London: Routledge and Kegan Paul, 1991.

27 Madeley RJ, Gillies PA, Power L, Symonds EM. Nottingham mothers stop smoking project - baseline survey of smoking in pregnancy. Community Medicine 1989: 11(2): 124-30. 
28 White A, Freeth S, O'Brien M. Infant Feeding 1990. Office of Population Censuses and Surveys. London: HMSO, 1992.

29 National Health Service Executive. Clinical guidelines: Using Clinical Guidelines to Improve Patient Care within the NHS. Leeds: NHS Executive, 1996.

30 McClarey M, Duff L. Making sense of clinical guidelines. Nursing Standard 1977: 12(1): $34-6$.

31 Duff LA, Kitson AL, Seers K, Humphris D. Clinical guidelines: an introduction to their development and implementation. Journal of Advanced Nursing 1996: 23: 887-95.

32 Agency for Health Care Policy and Research. Smoking Cessation. Clinical Practice Guideline. Agency for Health Care Policy and Research, 1996.

33 NHS Centre for Reviews and Dissemination. Smoking cessation. What the health service can do. Effectiveness Matters (The University of York) 1998: 3(1).

34 Law M, Tang JL. An analysis of the effectiveness of interventions intended to help people stop smoking. Archives of Internal Medicine 1995: 155: 1933-41.

35 McKenna H. The Delphi Technique: a worthwhile research approach for nursing? Journal of Aduanced Nursing 1994: 19: 1221-5.

36 Marsh A, McKay S. Poor Smokers. London: Policy Studies Institute, 1994.

37 Lawrence T, Evans O. A Randonised Controlled Trial to Evaluate the Effectiveness of Stage-based Interventions in Reducing Smoking in Pregnancy. Cardiff: Health Promotion Wales, 1998.

38 Lawrence T, Cheng KK, Evans O, Evans H. A Randomised Controlled Trial to Evaluate the Effectiveness of Stage-based Interventions in Reducing Smoking in Pregnancy in the West Midlands Health Region, England. (unpublished conference paper), November 1998.

39 New players for a new era-leading health promotion into the 21st Century. Jakarta 21-25 July 1997. In: Health Promotion International 1998: 12(3): 261-4.

40 King L, Hawe $\mathrm{P}$, Wise M. Making dissemination a two-way process. Health Promotion International 1998: 13(3): 237-44. 